disorders are often based on fuzzy, subjective and inconsistent criteria. The neuroscientists feel that such untargeted searches will be futile if the population labelled as having one condition — such as schizophrenia - in fact includes many different clinical disorders.

The antipathy is mutual. Some neuroscientists take what is to a geneticist an unacceptably small number of subjects - sometimes not even patients - and focus on establishing links between variants of a candidate gene and brain anatomy or function. Geneticists are often not persuaded by the statistics and question the focus on a few candidate genes whose link to disease has never been well established. Neither side seems to agree that the outcomes of the other's studies represent constructive leads. Nor is either side willing to compromise its standards. As a result, it is difficult to publish in the intersection between these two fields.

This conflict is unnecessary. Both communities will gain by learning from the other. Teams undertaking expensive genome-wide association studies should consult fully with clinical and research neuroscientists. If a single diagnostic label such as 'schizophrenia' is inadequate, then more detailed clinical information on patients must be collected when they are recruited. The studies might also benefit from more quantifiable measures of behaviour and neurobiology - such as laboratory assays of anxiety or the functioning of fear circuits in the brain.

And neuroscientists making early forays into genetic associations may find the hard lessons learned by geneticists over the years useful. Geneticists know about the statistical methods and criteria required to draw genetic conclusions that are persuasive and likely to stand the test of time.

The two sides should not lose sight of the fact that they share the same goal: to help patients. In the end, it is likely that both strategies and others will prove valuable in identifying risk factors and developing ways to counteract them. If genome-wide scans are appropriately designed and powered, they should yield the first clues. The neuroscientists' approach may then prove fruitful by showing what biological function is being performed by the genes identified, how that function leads to disease and how it can be altered.

When two fields such as these come together, lowering standards is not an option. Extracting psychiatric genes will require highly rigorous strategies, and on that geneticists and neuroscientists can agree.

\title{
A social contract
}

\section{Efforts to inform US military policy with insights from the social sciences could be a win-win approach.}

G iven the current US administration's notorious lack of respect for science, the efforts of defence secretary Robert Gates merit a mention. Gates took charge of the Pentagon in December 2006 and ever since has been trying to inform the military's thinking with researchers' insights into other cultures and societies. In October, for example, the Department of Defense launched the Human Terrain System (HTS) programme, in which teams of social scientists advise US troops operating in Iraq and Afghanistan. And on 30 June, the defence department signed a memorandum of understanding that will direct some of its money into social and behavioural science research through the National Science Foundation (NSF).

Gates's outreach may owe something to his tenure as president of Texas A\&M University in College Station for the four years before his current appointment. But it certainly reflects the hard lessons of Iraq and Afghanistan - where troops with insufficient understanding of the cultural or political landscape have too often exacerbated the insurgency they were trying to control.

With an HTS team, an anthropologist, say, might be present to advise a commander on the subtleties of negotiating with village elders in rural Afghanistan. According to Gates, one commander in Afghanistan says that using an HTS team has cut the number of armed attacks he has had to make by $60 \%$.

The recent NSF deal aims to shape the Pentagon's long-term strategic thinking by funding academic research in areas such as religious fundamentalism, terrorism and cultural change. Gates also hopes that such research could foster entirely new intellectual tools, in much the same way that work during the cold war fostered game theory.
All proposals will be selected for funding through the NSF's standard peer-review process. The research will be unclassified and no restrictions will be placed on researchers' freedom to publish their results - or for that matter, to criticize the defence department.

The two initiatives have received a decidedly mixed response. Some social scientists have enthusiastically embraced the goals of the HTS programme. But the American Anthropological Association (AAA) has formally condemned it, saying that participants would find it difficult or impossible to follow the association's ethical guidelines in a combat zone, and that it could make it more difficult for anthropologists to build trust elsewhere in the world.

The NSF agreement has been widely acclaimed by university administrators, who welcome the extra research money. But it has aroused the suspicion among some researchers that it will distort social science towards military priorities. Of particular concern is the fact that the defence department will have some say in the choice of the NSF's peer reviewers.

So far, Gates and his deputies have tried to be sensitive to these concerns. But continued vigilance is paramount. War is notoriously fraught with ambiguity and moral compromise, and it may well be a temptation for commanders to use the information gathered by HTS researchers to, say, target suspect populations. Such temptations should be resisted wherever possible: in the long run, honest dealings and the do-no-harm principle required by the AAA are in the military's own best interest. So too is avoiding any temptation to load the NSF peer-review panels.

Social scientists, meanwhile, should embrace the opportunities that the AAA pointed out last November in a report on engagement with the military. These include studying military and intelligence organizations from the inside and educating the military about other cultures and societies. Outrage at the current administration should not derail efforts that have potential to be a win-win for all concerned - including, most especially, the people of Iraq, Afghanistan and regions of future conflict. 